\title{
EREBEA
}

Revista de Humanidades

y Ciencias Sociales

Núm. 4 (2014), pp. 277-298

ISSN: 0214-0691

\section{El pronunciamiento de Huelva contra el General Espartero y el Sitio de Sevilla de i 843}

\author{
María Felisa Álvarez Rey \\ Universidad de Sevilla
}

\section{RESUMEN}

En el verano de 1843 se produjeron en Andalucía pronunciamientos contra la Regencia del general Espartero. En Huelva la Junta Central establecida intentó organizar y dirigir la insurrección. En julio de 1843 Sevilla se prepara para sufrir el asedio del general Van Halen y Huelva acude a ayudar a la capital bombardeada. Más de 600 bombas cayeron sobre la ciudad. Finalmente, se logra el fin de la Regencia y el establecimiento del reinado de Isabel II (1843-1868).
ABSTRACT

In the summer of 1843 the pronouncement is produced in Andalusia against the Regency of the general Espartero. The Central Board established in Huelva tries to organize and direct the insurgency. In July 1843 Seville is prepared to suffer the siege of the general VanHalen and Huelva comes to the rescue of the bombed capital. More than 600 bombs fall on the city. Finally, comes the end of the Regency and the establishment of the reign of Isabel II (1843-1868).
Palabras Clave

Espartero, pronunciamiento, bombardeo de Sevilla, Regencia Huelva, sitio de Sevilla, Van-Halen, Junta Central de Huelva (1843)

Fecha de recepción: 22 de abril de 2014 Fecha de aceptación: 23 de octubre de 2014
KEYWORDS

Espartero, pronouncement, bombard of Seville, Huelva Regency, siege of Seville, Van Halen, Central Board of Huelva (1843) 



\section{INTRODUCCIÓN}

Con la muerte de Fernando VII y la minoría de edad de su heredera, Isabel II, se inició en Espańa la época conocida con el nombre de las Regencias (18341843), durante la cual se produjo la definitiva implantación del liberalismo en nuestro país. A partir de esos años y en general hasta bien avanzada la segunda mitad del siglo XIX dos opciones políticas iban a aportar su propia interpretación sobre el nuevo sistema, disputándose alternativamente el poder: el Partido Progresista y el Moderado. ${ }^{1}$

La Regencia de María Cristina (1834-1840), viuda de Fernando VII, fracasó por su decidido apoyo al moderantismo; en 1841, tras finalizar con el triunfo de los isabelinos la Primera Guerra Carlista, los progresistas atrajeron a su causa al general Baldomero Espartero, quien asumió la Regencia entre 1841 y 1843 avalado por su gran carisma popular y por su condición de flamante vencedor de los partidarios de don Carlos². Sin embargo, instalado en el poder, el Regente reveló un marcado carácter autoritario adoptando medidas que disgustaron a prácticamente todos los sectores políticos. Durante los tres años que duró su mandato Espartero consiguió que las Cortes, la burguesía, la prensa... se aliasen contra él; incluso el ejército le negó el apoyo y la devoción que le habían brindado como jefe o caudillo militar. Progresistas y moderados alcanzaron un punto de coincidencia: acabar con la Regencia del general. Así, por toda Andalucía se iniciaron en el ve-

1 Sobre esta etapa de tránsito del absolutismo al liberalismo véase especialmente I. Burdiel, $L a$ politica de los Notables. Moderados y avanzados durante el régimen del Estatuto Real (1834-1836). València: Alfons el Magnànim, 1987; C. Marichal, La revolución liberal y los primeros partidos políticos en España, 1834-1844. Madrid: Cátedra, 1980 o A. Moliner Prada, Joaquín María López y el Partido Progresista (1834-1843). Alicante: Instituto Juan Gil Albert, 1987. Estudios más recientes en L. Garrido Muro, El nuevo Cid. Espartero, María Cristina y el primer liberalismo español (18341840). Tesis Doctoral inédita: Universidad de Cantabria, 2013.

2 Sobre Espartero véanse los estudios biográficos de M. Espadas Burgos, Baldomero Espartero. Un candidato al trono de España. Ciudad Real: Instituto de Estudios Manchegos, 1985; F. Bermejo Martín, Espartero, hacendado riojano. Logrońo: Instituto de Estudios Riojanos, 2000 y A. Shubert, "Baldomero Espartero (1793-1879): del ídolo al olvido", en I. Burdiel y M. Pérez Ledesma (coords.), Liberales, agitadores y conspiradores: biografias heterodoxas del siglo XIX. Madrid: Espasa Calpe, 2000, pp. 183-208. Sobre el progresismo en tiempos de la Regencia de Espartero cfr. especialmente M. Sierra Alonso, "Nación de un solo hemisferio: Las fronteras americanas de la representación a través de la vida de un exiliado", en Journal of Iberian and Latin American Research, vol. 20, no 1 (2014), pp. 111-125. 
rano de 1843 movimientos de oposición que adoptaron la ya característica forma del pronunciamiento: el 24 de mayo se pronunció Málaga, seguida poco después de Almería, Granada y Algeciras. A principios de julio la mayor parte de las principales capitales y ciudades andaluzas se habían pronunciado contra el Regente, pues solo Cádiz se mantuvo fiel a Espartero, duque de la Victoria.

El pronunciamiento anti-esparterista de Huelva: la Junta Provisional DE GOBIERNo

Sevilla y Huelva figuraron entre las ciudades que más tardíamente se sumaron al levantamiento contra Espartero, pronunciándose la primera el 17 de junio y Huelva el 26. ${ }^{3}$ Pese a la tardanza, lo cierto es que en ambas provincias se habían producido intentos fallidos con anterioridad a las fechas señaladas: en Sevilla, muy controlada desde el levantamiento que había protagonizado ańos antes, en noviembre de $1838^{4}$, se produjeron disturbios ya el 11 de junio, escuchándose los primeros "mueras a Espartero" y desarrollándose otros incidentes en los que participó activamente su Milicia Nacional. El desorden de hecho alcanzó tales proporciones que fue necesaria la intervención del Capitán General Carratalás.

Sucesos de índole similar habían tenido lugar ya el 3 de mayo en la ciudad de Huelva, en la que un grupo tocando un tambor y profiriendo gritos se enfrentó a un sereno para desarmarlo. La llegada de sus compañeros para auxiliarlo junto con una partida de seguridad consiguió disolver el grupo, practicándose varias detenciones y terminando el suceso con un herido de gravedad. ${ }^{6}$ Un goteo de incidentes parecidos continuaron repitiéndose durante el mes de junio en la capital onubense determinando que su jefe político, Juan de Luna, y el comandante militar Joaquín Zomoza decidieran adoptar acciones bastante duras: a las detenciones de revoltosos se sumó la orden de destierro para todo onubense que se manifes-

3 A pesar de que la primera mitad del siglo XIX y en especial la etapa de las Regencias presenta vacíos importantes en la historiografía andaluza pueden encontrarse enfoques de interés en obras como la coordinada por D. Caro Cancela (ed.), El primer liberalismo en Andalucía (1808-1868). Política, economía y sociabilidad. Cádiz: Universidad, 2005. Para la provincia de Huelva las principales aportaciones son las ofrecidas por M.A. Peña Guerrero, La provincia de Huelva en los siglos XIX y XX, vol. 4 de Varios Autores, El tiempo y las fuentes de la memoria. Historia moderna y contemporánea de la provincia de Huelva. Huelva: Diputación, 1998; J. Vega Domínguez, Huelva a fines del Antiguo Régimen: 1750-1833. Huelva: Diputación, 1995; J.L. Gozálvez Escobar, La formación de la provincia de Huelva y el afianzamiento de su capital. Huelva: Instituto de Estudios Onubenses, 1982, y especialmente los trabajos de V. Núñez García, "La insurrección progresista en Huelva durante el bienio 1835-1836", en Trocadero, no 16 (2004), pp. 127-147 y "Élites políticas en Huelva durante los inicios del régimen liberal: diputados y Diputación Provincial (1835-1868)", en D. Caro Cancela (dir.), El primer liberalismo. Loc. cit., pp. 127-155.

4 Fruto de una alianza del Ayuntamiento sevillano con su Milicia contra el poder establecido que obligó a la intervención de los generales Córdoba y Narváez.

5 Boletin Oficial de la Provincia de Sevilla (en adelante B.O.P de Sevilla), 12 de junio de 1843.

6 Boletin Oficial de la Provincia de Huelva (en adelante B.O.P de Huelva), 9 de junio de 1843. 
tase contrario a las directrices del gobierno presidido por Espartero. De hecho el día 21 de junio fue detenido y encarcelado el alcalde de Huelva junto con otros miembros relevantes de la capital, pasando a calabozos sin formación de causa.

Dos días después y con su alcalde aún detenido se reunió el Ayuntamiento onubense en sesión extraordinaria con la presencia de varias "personas respetables", acordándose emprender acciones para cooperar y auxiliar a las autoridades en el mantenimiento del orden público ${ }^{7}$. Entre las decisiones tomadas figuró la de cubrir con más personal los servicios diarios de guardia de la cárcel (muy nutrida desde las continuas detenciones practicadas por orden del jefe político y el comandante militar), organizándose a tal efecto turnos entre los vecinos y miembros de la milicia.

Desde Gibraleón, el 24 de junio, Juan de Luna se dirigió a la corporación de Huelva para decirle que "no solo apruebo sino que aplaudo las disposiciones que ese juicioso y cuerdo Ayuntamiento en unión de las respetables personas cuyos nombres constan... han adoptado con el objeto de conservar en la capital el orden público". El jefe político continuaba su escrito afirmando que en todos los pueblos de la provincia reinaba la tranquilidad; no obstante, sabemos que por esas fechas una partida dirigida por el sargento segundo de carabineros Juan Manuel del Río, con unos veinte hombres a caballo, intentó que primero la población de Almonte y el 23 de junio la de La Palma se levantasen contra el Regente ${ }^{8}$.

Mientras tanto en la Sevilla ya pronunciada su Junta provisional de gobierno, constituida el 19 de junio, atendía diversas comisiones de ciudades y pueblos que la requerían para apoyar el pronunciamiento en sus respectivas localidades. Entre las peticiones figuraba una comisión de Huelva; la Junta sevillana atendió su demanda y acordó enviar una columna expedicionaria a las órdenes de Manuel Pomar y Márquez, ${ }^{9}$ que unida con las fuerzas de la tropa de carabineros de la Hacienda Pública y con los milicianos nacionales de Escacena, bajo el mando del Coronel del provincial de Cádiz, lograron que triunfase el pronunciamiento contra Espartero en Huelva el 26 de junio de 1843.

7 Se acordó nombrar una comisión compuesta por Luis María Barrionuevo, Pedro Fonfreda, Elías Monis en su calidad de tesorero, Alejandro Ruifernandiz como contador de Rentas, Francisco Gálvez y Palacios, Manuel Quintero, Juan Vázquez, Prieto, Coromina, Bermúdez Alonso, José $\mathrm{M}^{\mathrm{a}}$ de Tresgallos y Bueno, Francisco Monteverde, José Primo de Rivera, Luis Ma López, José Ma Sánchez Chares, Francisco Ma Mete y Fernando de la Cueva. También integraron este organismo los comandantes de Marina, de la Milicia Nacional de Infantería y de Caballería, junto a Manuel Miliciano, representante de la empresa de sal de la provincia, actuando Miguel Antonio Reyes como secretario.

8 La Junta onubense, en la sesión del 15 de julio, concedió gratificaciones a Juan Manuel Ríos por su participación a favor del pronunciamiento en la provincia.

9 La Junta de Huelva, en la sesión del 28 de junio de 1843, le nombró comandante militar de la provincia. B.O.P. de Huelva, 30 de junio de 1843 
Ese día, en la sala de sesiones de la Diputación Provincial, se celebró una reunión presidida por el segundo alcalde constitucional Juan José Báez. En presencia de los diputados Miguel Montiel y José Morales, de representantes de la Milicia Nacional y de la mayoría de las personas notables de la ciudad, se abrió sesión manifestándose el deseo de nombrar una Junta de gobierno provisional para que Huelva secundase "los principios proclamados por la mayoría de la nación". En el transcurso de la reunión se decidió que el modo más conveniente sería elegir una comisión en la que estuvieran representadas todas las clases políticas y sociales de Huelva. Aprobada por aclamación la propuesta, se pasó a nombrar a los candidatos que debían constituirla entre regidores del Ayuntamiento, Milicia Nacional, militares, clero, miembros de la Diputación, magistrados, profesionales libres, propietarios, comerciantes, artistas, escribanos y empleados:

\section{Candidatos a representantes de las clases de Huelva}

26 DE JUNIO DE I 843

\section{*Por el Ayuntamiento:}

Juan José Baez

Pedro Benjumea

José Alonso

Pastor Garzón

\section{*Por la Milicia nacional}

Manuel Peláez

Patricio de la Corte

Manuel Chaves

Cristóbal Figueroa

*Por la clase militar

José Primo de Rivera

Pedro Fonfreda

Antonio Hernando

\section{*Por el clero}

León Antonio Coto

*Por la Diputación

Miguel Montiel

José Morales
Alcalde Segundo

Regidor

Regidor

Síndico

Teniente

Subteniente

Miliciano

Miliciano

Comandante Infantería

y Tesorero Rentas

Coronel Infantería

Capitán Carabineros

Presbítero

Diputado

Diputado 
*Por la Magistratura

Francisco Monteverde José Tresgallos

*Profesiones liberales

Manuel Miliciano

José Bermudez Cabrera

Luis María Barrionuevo

*Por los propietarios

José Bermúdez muños

Juan de Mora Villanso

Nicolás Vázquez

Miguel González

*Por el Comercio

Justos Santos

Hipólito Real

Antonio Martínez

Manuel Pérez Conde

*Por la de artistas

Manuel de la Torre

Francisco Gelvez

José Conomina

\section{*Escribanos}

Félix José de Bornas

José de la Corte

\section{* Por la Marina}

Andrés de Tostas

Cristóbal Carrión

\section{*Por la de Empleados}

José Ma Sánchez Chaves

Basilio Aranda

Manuel Ciudad

Manuel González

Francisco Mele

Leonardo Romero de Cisneros
Juez primera instancia

Asesor Rentas

Médico

Abogado

Médico
Comandante de la provincia

Intendente

Oficial $4^{\circ}$ de Gobierno

Oficial $2^{\circ}$ Contaduría Rentas

Administrador Puebla Guzmán

Contador de Rentas

Comisionado especial de ventas

de bienes nacionales 
Entre sus primeras decisiones la Junta de Huelva acordó premiar los servicios prestados por la columna de carabineros de Hacienda y milicianos nacionales de Escacena, que al mando del Coronel del provincial de Cádiz "había liberado a la provincia de los males que la amenazaban, protegiendo los principios proclamados en el pronunciamiento" ${ }^{10}$ y sin perjuicio de oficiar a los respectivos jefes para que propongan los premios a que cada individuo se hubiera hecho acreedor. Seguidamente remitió un comunicado a la Junta de Sevilla anunciándole el triunfo de su alzamiento y agradeciéndole su ayuda. La Junta de Gobierno de Sevilla le remitió a su vez "su más sincera y cordial enhorabuena por haber sacudido el yugo que le impusieran autoridades despóticas"11, complaciéndose por haber contribuido al triunfo del pronunciamiento.

La Junta Provisional de Gobierno de la Provincia de Huelva se dirigió así a sus habitantes el 26 de junio de 1843 :

"En Huelva, ya lo sabéis habitantes de ésta provincia, varios distinguidos patriotas han sufrido la más injusta deportación y hoy se encuentran en un castillo privados de la libertad sin otra formalidad que el arbitrario mandato de los que fueron jefe político y comandante militar de la misma, ni otro motivo que la presunción de que los animara el más vivo deseo de secundar los esfuerzos de nuestros hermanos...La Junta recomienda la conservación del orden público y confía en la sensatez y cordura de la Milicia nacional que contribuirá eficazmente a tan indispensable objeto para no ver malogrado el fin de nuestros comunes conatos. Igualmente confía en el celo de las autoridades que cooperaran en el mismo intento y que le prestarán espontáneamente todos los auxilios que las circunstancias exijan.

La Junta además no puede dejar de dar un voto de gracias a la columna del valiente ejército de Carabineros del reino y Milicia Nacional de Escacena que poniendo en fuga a los déspotas que aquí nos oprimían reanimó el espíritu público y nos ofrece garantía de seguridad contra las tramas de los mismos"12.

La justificación del levantamiento fue argumentado del siguiente modo:

"Demasiado públicas son las justas causas que han provocado el alzamiento ya casi unánime de toda la nación contra el tiránico bando que pretendía conducirnos a la más ominosa tiranía. Pueblos heroicos y esforzados

10 Sesión 30 de junio de 1843. B.O.P de Huelva, 5 de julio de 1843. La junta onubense en su Sesión 13/7/1843 concedió grados, empleos y cruces a los que compusieron dicha columna.

11 Sesión 1 de julio de 1843. B.O.P de Huelva,7 de julio de 1843.

12 B.O.P de Huelva, 30 de junio de 1843. 
que conociendo los riesgos de la situación, ni un momento dudaron presentase a los costosos sacrificios que la salvación de la patria exigía. Huelva, celosa por demás también del exacto cumplimiento de los derechos que a los españoles conceden la Constitución del Estado vilmente holladas no puede permanecer pasiva al grito que por todos los ángulos de la península resonará. Huelva ha secundado el movimiento general pero a su vez no debe ser estéril en las naturales consecuencias que necesariamente debe producir. El común enemigo, aunque muy debilitado porque el ejército hijo del pueblo reconociendo la justicia de sus quejas se va uniendo como no podía ser menos a la causa nacional, aún conserva fuerzas imponentes contra lo que es indispensable estar preparado. Huelva debió seguir el ejemplo de las demás provincias pronunciadas... ${ }^{13}$

Días después, el 3 de julio de 1843, quedo constituida la Junta Central de Huelva conformada por los siguientes miembros:

\section{Junta Provisional de Gobierno de Huelva 3 DE JULIO DE I 843}

\section{CARGO}

PRESIDENTE: VICEPRESIDENTE:

VOCALES:

\section{NOMBRE}

José María Morales

José Primo de Rivera

Miguel Montiel ${ }^{14}$

José $\mathrm{M}^{\mathrm{a}}$ Tresgallo y Bueno Comandante accidental

Milicia nacional y Asesor

Rentas

Pedro Pérez Ponce

Luis María Barrionuevo

León Antonio Coto

Manuel Chaves

Félix José de Bormes ${ }^{15}$
Abogado fiscal de la subdelegación de

Rentas. Vocal vicesecretario

Médico y Cirujano

Presbítero

Oficial Diputación

Provincial

Escribano subdelegación

Rentas

VOCAL SECRETARIO:José Moreno

13 B.O.P de Huelva, 5 de julio de 1843

14 El 10 de septiembre de 1843 fue nombrado por la Junta jefe del gobierno político sin sueldo

15 Presidente interino tras detención del alcalde constitucional el 21/07/1843 
En la sesión del 30 de junio la Junta acordó organizar los trabajos pendientes en tres comisiones: Sesión de Armamento y Defensa a cargo de Luis Maria Barrionuevo, José María Tresgallos y Pedro Pérez Ponce; Sesión de Hacienda y Comunicaciones externas formada por José María Morales, Félix José de Bormes y José Primo de Rivera y la Sesión de Despachos ordinarios conformada por Miguel Montiel, León Antonio Coto, José Moreno y Manuel Chaves.

La Junta de Huelva, además de afrontar la tarea de encontrar y nombrar personas idóneas, tuvo que emplear todas sus fuerzas en tratar de hacer prevalecer su autoridad sobre los pueblos de la provincia. En estas localidades, pronunciadas contra el Regente, se crearon igualmente Juntas que fueron quienes tomaron las riendas de los asuntos locales y organizaron sus Ayuntamientos. Para la Junta de Huelva resultaba imprescindible concentrar en sus manos todas esas parcelas de poder y lograr el reconocimiento de su superioridad, con el objeto de dirigir las decisiones que concernían tanto a sí misma como al conjunto de la provincia. A esta labor dedicó desde el primer momento todos sus esfuerzos y a este fin respondieron las diversas Circulares que se hicieron llegar a las Juntas de los pueblos pronunciados, del tenor de ésta que reproducimos a continuación:

\footnotetext{
"Habitantes de la provincia de Huelva: olvidad en este momento en que la salvación de la patria os llama y necesita, ańejos resentimientos: sacrificadlos en las aras del bien público: seguid el noble y generoso ejemplo de todas las capitales de reino y de amigos sinceros de la libertad. ¡Unión! Porque de ella depende nuestro invencible fuerza. Unión y libertad. Viva la Constitución de 1837; Viva la Reina constitucional; Viva el programa del Ministerio López: viva la Unión de todos los españoles. Huelva, 14 de julio de $1843 "{ }^{16}$
}

No faltaron llamamientos en los que se les invitaba amablemente a reconocer a la Junta Central establecida en la capital, ofreciéndoles el cargo de Juntas Auxiliares no sin antes agradecerles el "haberse lanzado noblemente a sacudir el yugo que intentaban ponernos, y salvar al país y a la Reina" ${ }^{17}$.

Estas peticiones obtuvieron resultados positivos y la comisión encargada de Armamento y Defensa recibió comunicaciones de pueblos de la provincia expresando su adhesión al pronunciamiento, entre ellas las de San Juan del Puerto, que remitió copia del acta y adhesiones expresas de su Milicia Nacional y personas respetables. Por su parte el Ayuntamiento de Ayamonte, que lo verificó el día 27, apoyado por su Milicia Nacional, el juzgado de primera instancia y la poca fuerza del ejército de que disponía, explicaba en su escrito que el gobernador de la plaza 
no había tomado parte activa pero tampoco se había opuesto al levantamiento. Gregorio Arrayal, promotor fiscal del partido de Ayamonte y Luis María Villar, subteniente cesante de carabineros, ofrecieron a la Junta sus servicios. Los ayuntamientos de Lucena, Beas, Palos, Bonares, Redondela, Trigueros, Bartolomé de la Torre y Aljaraque (incluido su cura), anunciaron a la Junta Central de Huelva su adhesión al pronunciamiento contra el Regente y en Cartaya, el día 27, rubricó dicha adhesión el comandante de su Milicia Nacional junto con oficiales, las autoridades locales y carabineros, tanto sus comandante de armas como oficiales retirados. Este Ayuntamiento informó además que había nombrado a José Parra y Rubio administrador de Aduanas de la villa, puesto que el anterior administrador, Eugenio Sanjurjo, la había abandonado. También comunicó la deposición de sus destinos de los empleados de la Hacienda, Antonio Castañeira -que era oficial de la Administración principal de rentas-y del referido Eugenio Sanjurjo, administrador de la Aduana "no solo por el comportamiento que han tenido durante la dominación tiránica del jefe político y comandante general que fueron de esta provincia, sino también por haber abandonado sus puestos incorporándose a las tropas reducidas. "18

Igualmente secundaron el pronunciamiento contra Espartero los Ayuntamientos de Cabezas Rubias y El Cerro con su corporación, Milicia Nacional y personalidades del pueblo, a excepción de su Juez de primera Instancia, Francisco González Cortes. En Sanlúcar de Guadiana se adhirió el gobernador del castillo que guarnecía la localidad y el destacamento de artillería. En Moguer lo hizo su Ayuntamiento, autoridades militares y de marina, la Milicia Nacional, personas notables y el oficial de carabineros Pedro Bargayo, con la fuerza bajo su mando.

En la capital mientras tanto también reconocieron y se adhirieron a la Junta recién constituida el Vicario eclesiástico y todos sus dependientes; el Intendente y todos los empleados de las oficinas de Hacienda, el Comandante Militar de Marina de la provincia y todos los empleados del ramo residentes en la capital. En sesión celebrada ya el 19 de julio se recibió comunicación de los pronunciamientos llevados a cabo en Berrocal, Campofrío, Cañaveral, Chucena, Corteconcepción, Cortelazor, Cumbres Mayores, Encinasola, Gibraleón, El Granado, Hinojales, La Granada, Lepe, Linares, Manzanilla, La Nava, Puerto Moral y Villanueva de los Castillejos. En Puebla de Guzmán por su parte se acordó el cese de los concejales de su Ayuntamiento, siendo sustituidos por los nombrados en 1838, devolviéndose algunas tierras a vecinos que habían sido despojados de ellas.

Hubo no obstante personas, empleados públicos y autoridades, que no secundaron el levantamiento anti-esparterista en Huelva, entre ellos el oficial de aduanas Antonio Castańeiras; los de Contaduría Luis Sánchez Pérez, Cayetano Díaz, Zacarías López y el estanquero de la capital Antonio Ramírez de Aguilera, 
todos los cuales fueron separados de sus empleos. Al oficial primero de la secretaría del gobierno político de la provincia, Francisco Rayan, se le destituyó de su destino "no solo por la conducta observada durante la tiránica dominación del jefe político y comandante general que fueron de la provincia, sino también por haber abandonado su puesto siguiendo a las tropas reducidas." ${ }^{19}$ Por otro lado, no faltaron quejas como las remitidas a la Junta de Huelva y leída en la sesión del 8 de agosto por vecinos de Santa Olalla contra su propio Ayuntamiento, al que acusaban de falsedad en el acta del pronunciamiento y suplantación de firmas.

Mención aparte merece el Ayuntamiento de Ayamonte, que en comunicado fechado el 14 de julio de 1843, firmado por su presidente Manuel Silesio y por José María García, José Antonio Castellano, José María Aguilera, Juan Antonio Espańa y Javier Granados como secretario, expresaban de una manera muy crítica su disconformidad con la forma de actuación política de la Junta Superior de Huelva, a la que no dudaban en calificarla de partidista:

"Esta Comisión compuesta de hombres independientes, y en su mayor parte de fortuna, no aceptó los compromisos de su posición para apoyar pretensiones personales ni exigencias que no sean las del bien público. Comprende su misión de muy diferente manera”. ${ }^{20}$

Al mismo tiempo, la Junta Auxiliar de Ayamonte reclamaba una participación de los pueblos pronunciados en la Junta Central, solicitando que se verificase la reinstalación de la Junta Superior haciendo uso de las formas democráticas:

\footnotetext{
"Esta Comisión y con ella la mayoría de esta ciudad cree que esa Excma. Junta debe ya componerse de los representantes de cada uno de los pueblos que forman sus partidos, y lo cree así, porque estas son las prácticas de un gobierno representativo, por cuya salvación nos hemos levantado. Lo cree así, porque no de otro modo se salva el escrúpulo de los hombres verdaderamente amantes de la Constitución, y se quita el pretexto que los menos ardientes defensores de ella pudieran tomar para no prestarse a toda clase de sacrificios con la ingenuidad que la salvación del país exige."21
}

\section{La Junta Superior de Gobierno de la provincia de Huelva}

Muy en serio se tomó la Junta provisional de Huelva las actuaciones contrarias a sus disposiciones y por ello desde un principio su alcalde, José María Morales, decretó que cualquier persona que de algún modo tratara de amortiguar el entu- 
siasmo patriótico, propagando expresiones alarmantes, sería tratado como traidor y castigado con sujeción a las leyes. No obstante, dos fueron los focos principales de atención de la recién instalada Junta onubense: conseguir fondos suficientes con los que atender sus necesidades más perentorias y defender la seguridad de sus conciudadanos.

En relación al primer punto, la falta de efectivo fue un mal que limitó la actuación de la Junta de Huelva y que le impidió realizar un programa más ambicioso. Los planes diseñados por la Junta para allegar recursos resultaron infructuosos y ante esta situación los principales cargos otorgados por la Junta provisional se hicieron a título no oneroso. Por otra parte desde un principio la Diputación Provincial alertó que no contaba con fondos para cubrir sus más precisas e indispensables necesidades, por lo que solicitó que a la mayor brevedad se le hiciera efectiva la suma que a cada pueblo le estuviera señalado en el repartimiento de ese año. La Diputación exhortó al patriotismo de los pueblos, pero avisando de que caso de no obtener una respuesta positiva emprendería medidas coercitivas. ${ }^{22}$

La Junta, ante la escasez de fondos existentes, propuso reclamar a las corporaciones municipales el tercer trimestre a devengar de todas las contribuciones, exigiendo a los arrendadores de los ramos de rentas provinciales las cantidades que figuraran como adeudadas. También se acordó pedir al representante de la empresa de sal de la provincia la cantidad de 10.000 reales en el término de 24 horas, amenazando de no ser atendida con llevar a efecto la intervención de la venta de sal en Isla Cristina. La Junta lamentó que la tropa residente en Huelva se quejara de la mala calidad del pan que se le suministraba y para remediar esto acordó oficiar al Comandante General con el fin de que adoptara las medidas necesarias.

En la sesión del 13 de julio la Junta tuvo que reconocer que las medidas económicas adoptadas habían sido insuficientes, por lo que llegó a dictar providencias aún más enérgicas con el objetivo de reunir fondos para cubrir sus necesidades: dio un plazo improrrogable de cuatro días para hacer efectivas las contribuciones devengadas, amenazando con apremios inmediatos. Aún así, las quejas contra la falta de recursos económicos continuó siendo una constante en las sesiones celebradas por este organismo.

La segunda preocupación invariable en la existencia de esta Junta de Huelva fue la necesidad de contar con efectivos militares suficientes capaces de defenderla. Para lograrlo centró sus esfuerzos en tres frentes: renovación de quintas, creación de un cuerpo franco de voluntarios y la movilización de la Milicia Nacional. El 5 de julio de 1843 la Junta se dirigió así a los onubenses:

“¡A las armas! Una fracción de españoles tan inmoral como escasa en méritos y valimientos os ha oprimido y provocado...Allá en el nuevo 
mundo os arrebató en Ayacucho un continente inmenso acá ahora en el antiguo intentó permutar la independencia y nuestra industria, por unas cuantas guineas que ellos solo recogieron; nuestra libertad, compatriotas por los oropeles y los sueldos de quienes siguen al bando maldecido.

Onubenses: si circula en vosotros todavía la sangre de los Corteses y Pinzones, que zarparan de vuestros puertos; si circula aquella sangre que ilustró las almenas de la noble Niebla, acudid, acudid presurosos a la lucha, que la inocencia y el trono de Isabel II lo reclaman; acudid, que la libertada se salve, que la patria lo manda.

A las armas onubenses, el triunfo es seguro y pronto, y que la España deba parte a vuestros brazos de aquella gloria y poder que le legaron los inmarcesibles pendones de San Fernando y de los Reyes Católicos, y que vamos a recuperar con vuestra irrevocable determinación..."23

Para cumplir el primer punto la Junta se apresuró a llevar a cabo el llamamiento de jóvenes a quintas repitiendo el cupo correspondiente a la provincia en la convocatoria del año anterior. Los nuevos soldados de reemplazo debían hacer entrada en la capital el 13 de julio; en caso necesario se tenía previsto implantar el alistamiento forzoso. ${ }^{24}$ En un principio se estimó una cifra de 800 hombres por repartimiento; en los pueblos el número resultaría según la base de su población a tenor del último censo, no considerándose exentos a los hombres de mar.

El cuerpo franco por su parte pretendía nutrirse con voluntarios licenciados del Ejército y personas no obligadas a quintas. Francisco Terreiro, Pedro Regalado, Francisco Vázquez e Ildelfonso Aurides fueron los encargados de su formación, reservándose la Junta el nombramiento del jefe del cuerpo. En este sentido se realizó un llamamiento a oficiales y militares retirados exigiéndoles que en veinticuatro horas y por escrito manifestasen si se adherían al pronunciamiento del 26 de junio. El cuerpo franco contaría con una dotación de 26 reales por hombre y todos los que solicitasen formar parte del mismo debían ser licenciados del Ejército o de la Milicia provincial, tener una edad máxima de 35 ańos y más de 18 y hasta 30 años los paisanos procedentes de la Milicia. Los candidatos debían ser solteros o viudos sin hijos y tendrían que acreditar su edad y certificado de buena conducta expedido por su Ayuntamiento. Los admitidos servirían el tiempo que se considerara conveniente por la Junta y estarían dispuestos a prestar su servicio en el lugar que se les destinara. La Junta llegó a contemplar el caso de que si estos voluntarios fueran llamados a quintas le sería descontado de su servicio el tiempo prestado en el cuerpo franco. 
En relación a la Milicia Nacional y por las medidas adoptadas por la Junta podemos deducir que ésta institución se encontraba en Huelva si no en crisis, sí un tanto desorganizada ${ }^{25}$. Nos basamos para esta afirmación en las repetidas alusiones al año 1837, como última movilización realizada por la Milicia onubense, y a 1834, como la última fecha de recepción de armamento y correajes. Para reactivarla la Junta declaró milicianos nacionales a todos los mozos solteros y viudos sin hijos con edades comprendidas entre los 18 y 24 años inclusive, pretendiendo conformar la cifra de unos 800 hombres aportados por los distintos pueblos de la provincia en relación a su censo de población. La Diputación señaló el día en el que los distintos Ayuntamientos habrían de celebrar el sorteo y declaración de movilizados: éste procedimiento debía comenzar el 20 de julio y completarse el 30 del mismo mes. De este reparto extraordinario no quedaba excluido ningún hombre de mar, pero si se declararon exentos a los marineros que acreditaran haber hecho una campaña o que la estuvieran verificando por sustitutos, y a los Cuerpos de Carabineros del Reino. El servicio podía redimirse por sustitución personal, pero para ser admitido el sustituto debía presentar su partida de bautismo y certificado de buena conducta expedido por su Ayuntamiento. Aunque no se exigía talla alguna a los sustitutos se les exigía tener "la robustez necesaria". En caso de que el movilizado no se presentase se le impondría a su padre una multa de 2.000 reales para gastos de guerra, sin perjuicio de procederse a la busca y captura del mozo y a la imposición de una pena severa. En caso de que el padre no poseyera bienes con los que abonar la sanción se le impondrían cuatro meses de prisión en la cárcel de la capital. Los milicianos cobrarían cuatro reales diarios; cuatro y medio los cabos segundos; cinco reales los primeros; cinco y medio los sargentos segundos y seis reales los sargentos primeros. A los oficiales les corresponderían los mismos sueldos que a los oficiales del Ejército. Con estas disposiciones la Milicia Nacional de Huelva comenzó a tomar forma, viéndose engrosada con los efectivos llegados de los pueblos de la provincia. En este sentido destacó la colaboración prestada por el Ayuntamiento de Cartaya, que aportó 30 milicianos de infantería; sabemos también que la Milicia de Ayamonte contó con una dotación económica de 2.000 reales.

Especial atención se otorgó al cuerpo de caballería de la Milicia Nacional, solicitando la Junta un estudio pormenorizado sobre su estado para proceder a su reorganización: inventario sobre su armamento, correajes y estado en el que se encontraba; número de individuos solteros, viudos con y sin hijos y casados que la integraban y número de individuos con montura. Se decidió excluir de dicha arma a aquellos milicianos que no tuvieran caballos capaces para el servicio, exigién-

25 El comandante de la Milicia José Tresgallos, el 26 de junio de 1843, reclamó al Ayuntamiento la devolución de la caja del cuerpo que le fue extraída de su casa, calificando tal acto de ofensivo que "hiere la delicadeza y el honor de cuerpo". 
dose a los animales una alzada mínima de seis pulgadas y media. Los milicianos de caballería que fueran excluidos de este cuerpo pasarían inmediatamente al de infantería.

A pesar de estas disposiciones la Junta de Huelva tropezó con dificultades para llevar a cabo las movilizaciones y quintas requeridas. El nombramiento de una comisión especial formada por Manuel Chaves, Pedro Pérez Ponce y León Antonio Coto no pareció mejorar la situación. Incluso algunos miembros de la Junta, como Barrionuevo, expresaron su disconformidad por el hecho de que los matriculados del mar no estuvieran exentos de la movilización. A esta protesta se unió las reclamaciones formuladas por el Comandante de Marina y los representantes del gremio de matriculados. En sesión del 5 de julio se leyó un oficio remitido por la Junta sevillana en la que expresaba su deseo de que la columna enviada a Huelva al mando de Pomar continuara en la capital onubense a pesar de la falta que hacía en Sevilla, pero sin descartar una pronta movilización de la misma para resistir a la contraofensiva de Espartero, dirigida por Van-Halen ${ }^{26}$. Desde Huelva se acordó contestar que agradecía a los sevillanos el interés que se tomaba por esta provincia, anunciándoles que se trabajaba sin descanso para la organización de fuerzas que muy pronto esperaban que se encontrasen preparadas.

Entre las medidas defensivas adoptadas por la Junta onubense destacaron las encaminadas a proteger los puntos más estratégicos de su costa. Para ello se contó con el indispensable apoyo de la empresa de guardacostas y del comandante de Marina de la provincia, quienes expresaron su decidido apoyo al pronunciamiento poniendo sus jefes y buques a las órdenes de la Junta ${ }^{27}$. Este sostén fue de gran importancia tanto por la fuerza disponible como por la garantía que suponía para la defensa.

No obstante, las dificultades de la Junta para allegar recursos con que organizar la defensa militar de la provincia quedaron patente en la sesión celebrada el 13 de julio de 1843. En ella se informó que aún no se había recibido en el depósito de la capital todo el armamento, correajes y municiones solicitados a los pueblos; de la falta de oficiales de instrucción que organizaran las compañías que se estaban formando y de la imposibilidad de entrenarlas en tan poco tiempo. La Junta decidió instar una vez más a los pueblos para que entregaran dichos suministros e hizo una nueva invitación a los oficiales retirados a prestar su servicio en las fuerzas que se estaban creando. Por su parte, el jefe de la segunda compañía de infantería de carabineros también manifestó a la Junta las urgentes necesidades que sufría la tropa bajo su mando, por no haber recibido el completo de sus haberes desde el mes de mayo.

26 Véase al respecto M.F. Álvarez Rey, El primer liberalismo en Sevilla. Las Regencias de María Cristina y Espartero (1833-1843). Sevilla, Ayuntamiento/ICAS, 2006; especialmente el capítulo "Sevilla bajo las bombas: el pronunciamiento de 1843", pp. 148 y siguientes.

27 B.O.P de Huelva de 2 de julio de 1843. Sesión del día 29 de junio de 1843. 
Tres días después de esta sesión, el 16 de julio de 1843, la Junta además ordenó la desmovilización de la Milicia Nacional de Huelva, fundando su decisión en lo necesario que eran dichos brazos jóvenes en las tareas de recolección:

"Habiéndose cesado por ahora las graves circunstancias que pusieron a ésta Junta, bien a su pesar, en necesidad de llamar a la capital a todas las nacionales solteros y viudos sin hijos para defender el noble pendón enarbolado en el pronunciamiento, y deseando que los brazos que tanto hacen falta en la presente estación para la recolección de las mieses, vuelvan a ocuparse de sus trabajos ordinarios..." 28

La calma que se vivía en Huelva y su provincia contrastaba sin embargo con los acontecimientos que se estaban viviendo Sevilla. Por esas fechas la capital hispalense se preparaba para hacer frente a las tropas del Regente que lideradas por el general Van-Halen se dirigían a la ciudad. La fama precedía a este general, responsable del bombardeo de Barcelona, de tal manera que no eran exagerados en absoluto, como luego pudo comprobarse, los temores de las autoridades locales sevillanas. Por ello el capitán general del distrito le comunicó a la Junta onubense que había ordenado el regreso inmediato a Sevilla de la columna del brigadier Pomar, recientemente nombrado comandante general de Huelva.

\section{El bombardeo de Sevilla}

El 18 de julio de 1843 los vigías desde la Giralda avistaron cómo las tropas del general Van Halen se encaminaban hacia Sevilla por el camino de Torreblanca. Al día siguiente se produjo el primer combate en la Cruz del Campo, abriendo fuego de cañón las tropas del Regente en su intento de adelantar posiciones hacia el centro de la ciudad, provocando la retirada de la vanguardia sevillana. Para detener dicho avance la artillería establecida en la Puerta Osario tuvo que emplearse a fondo, a pesar de lo cual Van Halen consiguió situar sus tropas frente a dos puertas de las murallas de la ciudad: Osario y la de Carmona.

Durante ocho días Sevilla fue sometida a un duro asedio, cayendo sobre la ciudad más de 600 bombas. Las fuerzas de ambos contrincantes no podían ser más desiguales: de un lado los sitiadores, militares profesionales, bien instruidos y disciplinados; del otro civiles armados y desbordados por la situación, junto a algunas compañías de soldados adheridos al pronunciamiento y milicianos con una cierta instrucción y conocimientos militares. La Junta sevillana pidió ayuda a las localidades de su provincia obteniendo una débil respuesta, por lo que se vio obligada a reunir todas las fuerzas disponibles, entre ellas, como hemos mencionado, la columna al mando del brigadier Pomar destinada en Huelva y que retor- 
nó el 20 de julio. Pero esta unidad no regresó sola, sino acompañada de fuerzas onubenses que ayudaron en la medida de sus posibilidades: "Huelva no puede manifestarse tranquila al ver a sus hermanos en peligro", fue el mensaje remitido por las autoridades de dicha provincia. Los onubenses llevaron además a Sevilla pólvora, ${ }^{29}$ de la que se andaba muy necesitada, y una cureña o armazón de madera para montar un cañón que fue instalado a la derecha de la Puerta Carmona, desde donde prestó un importante servicio defensivo al tratarse de uno de los puntos más atacados por los sitiadores.

El día 21 en Sevilla fue terrible: las bombas caían sin parar y por toda la ciudad se derrumbaron edificios, ardieron iglesias, afectando el bombardeo a casas de particulares y conventos y provocando varios muertos y heridos. Muchos sevillanos huyeron hacia Camas, Castilleja, San Juan y Gines. El día 22 los vigías anunciaron la llegada de Espartero, lo que explicaba la crudeza con que se había empleado Van-Halen en su intento de rendir Sevilla. Pero pese a su empeńo no lo consiguió. El Regente ofreció una rendición honrosa pero la Junta sevillana no lo aceptó.

Espartero probó nuevas tácticas para abrir brecha en la muralla y diseñó una maniobra envolvente que hizo emplearse a fondo a los defensores, sustituyéndose el ruido de los cañones por el de fusil. Pero ya era demasiado tarde: se había logrado la victoria de Torrejón y Espartero, el 27 por la noche, emprendió la retirada y comenzó una rápida huida hacia Cádiz.

Por su cercanía y por los tradicionales lazos existentes entre ambas provincias, Huelva no vivió el sitio sufrido por Sevilla como un hecho ajeno. En este sentido, la respuesta dada por las autoridades onubenses no ofreció ninguna duda, manifestando desde un principio su apoyo a los sevillanos y aportándole refuerzos humanos y materiales dentro de sus posibilidades. A estas circunstancias correspondió la emisión del siguiente bando por la junta de Huelva, y que a continuación reproducimos:

"Los feroces enemigos de nuestra patria sedientos de sangre y oro, conociendo su impotencia, ha principiado ya a bombardear la más hermosa y rica de las capitales de Andalucía sin atreverse llegar a sus muros. Sevilla hoy con valor y heroísmo está sufriendo las consecuencias del proceder vil y cobarde de esos nuevos vándalos a cuyo frente se haya el destructor de Barcelona. Pero Sevilla no se rendirá, porque hierve en el pecho de sus moradores el entusiasmo más puro y noble. Huelva sin embargo no puede manifestarse tranquila al ver a sus hermanos en peligro, y la junta provisional

29 El batallón de Huelva que participó en la defensa de Sevilla estuvo al mando del teniente Luis María Villar. 
de gobierno que rige interinamente los destinos de la provincia, confía en el patriotismo y cordura de todos sus habitantes;... ${ }^{30}$

Huelva, 22 de julio de 1843.

Por su cercanía Huelva debió vivir la intranquilidad de unas fuerzas amenazadoras tan cercanas, y a este temor respondía el siguiente articulado:

“... más para contener los desmanes que en tan críticas circunstancias puedan promover los enemigos de nuestra libertad, ordena y manda:

$1^{\circ}$ Todo movilizado quinto o licenciado que se separe de las filas, ahuyentándose de ésta capital, sufrirá irremisiblemente la pena de muerte.

$2^{\circ}$ En igual pena incurrirá todo individuo que esparza voces alarmantes y que puedan calificarse con tendencia a apagar el patriotismo y a introducir la desconfianza y el terror.

$3^{\circ}$. Los promovedores o auxiliadores de asonadas o tumultos, sea el objeto cual fueses, que a la primera invitación que las autoridades les dirijan, no se retiren estableciendo la tranquilidad pública, serán reputados como traidores y juzgados según el artículo siguiente.

$4^{\circ}$ Todo el que incurra en los delitos marcados en los artículos anteriores, será juzgado breve y sumariamente por una comisión militar ejecutiva que queda nombrada al efecto. Huelva, 22 de julio de 1843 "31

La Junta sevillana fue conciente del apoyo demostrado por su homóloga onubense y tan solo unas horas después de librarse del asedio, remitió una comunicación en la que les daba sinceras gracias por su celo, patriotismo y decisión y por su ofrecimiento de envío de tropas para auxiliar a Sevilla durante el sitio. La junta sevillana le comunicó que ya no eran necesarios sus refuerzos "porque hoy a la madrugada el enemigo levantó el campo" ${ }^{32}$

La carta que la Junta de Huelva remitió a la de Sevilla, felicitándola por el triunfo contra el Regente, puede considerarse como una de las de mayor interés de entre las muy numerosas recibidas de todas partes de Espańa y conservadas en los archivos hispalenses. Su importancia, junto a la remitida por Cádiz, ${ }^{33}$ estriba en que por la cercanía entre ambas localidades, Huelva tuvo una visión muy próxima no solo de los

30 B.O.P de Huelva de 2 de agosto de 1843. Felix José de Bormas, presidente interino. Miguel Montiel, Luis María Barrionuevo. José María Tresgallo, León Antonio Coto. Manuel Chaves. Pedro Pérez Ponce, José Moreno, vocal secretario.

31 B.O.P de Huelva de 2 de agosto de 1843.

32 Sesión 2 de agosto de 1843.

33 Cádiz, fiel al Regente, proporcionó las bombas que fueron arrojadas sobre Sevilla. El Ayuntamiento gaditano, junto a su felicitación, ofreció sus explicaciones y disculpas a los sevillanos. 
acontecimientos desarrollados en Sevilla, sino también de los sufrimientos, las muertes y la destrucción causada por los sitiadores. Reproducimos parte de su contenido:

Excmo. Sr. La Junta de Gobierno de esta provincia identificada con V.E en sentimientos y principios, faltaría a uno de sus más elevados deberes, sino se apresurase a felicitar cumplidamente a V.E por el glorioso triunfo que ha conseguido esa ciudad contra las huestes de la tiranía, y por el celo y energía que al intento $\mathrm{V}$. E ha desplegado.

Sevilla, la inmortal Sevilla, la primera que en el espacio de nueve años ha abatido el orgullo de Espartero, ha añadido a su historia en esta ocasión la página más brillante con que puede envanecerse una ciudad. Sus bravos defensores, los libres sevillanos han dado a los déspotas de la tierra la terrible lección de que son estériles todos sus esfuerzos para unir a un pueblo al carro de la ignominiosa servidumbre, cuando ha jurado y quiere su libertad e independencia...

Manes de Sagunto, de Numancia, de Tarifa, de Zaragoza y demás ínclitas ciudades gloria y ornamento de la nación espańola, levantaos y decidnos, si tienen algo que envidiaros en constancia, en sufrimiento, abnegación bizarría los heroicos defensores de la Seńora del Betis. Ellos como vosotros han orlado sus sienes de inmarcesible gloria, y sus nombres pasarán con respeto a la posteridad como han pasado los vuestros. ¡Gloria y loor a los nuevos Numantinos! ¡Gloria al Excmo. Sr. Capitán general que con una actividad y pericia admirables, se ha hallado en todas partes animando con su ejemplo a los valientes! ;Gloria en fin a V.E. que con su celo infatigable, sus acertadas medidas, su firmeza y serenidad imperturbable, ha llevado a feliz término la grandiosa obra que sus conciudadanos le encomendaros, elevándose a la altura de los verdaderos padres de la patria, y para lo que los individuos que componen esa Junta ocupan ya un lugar eminente en el templo de la inmortalidad!..... ${ }^{34}$

Huelva, 30 de julio de 1843.

La Junta de Huelva, compadecida de la situación en la que habían quedado tantos sevillanos, emitió una circular en la que pedía se abriera en toda la provincia una suscripción voluntaria para socorrer a las familias pobres que habían padecido la defensa de aquella capital. La Junta onubense llamaba a sus Ayuntamientos a ejercitar el patriotismo y filantropía que exigían los acontecimientos, proponiéndoles "que el acto al que se le invitaba los haría de algún modo participes de los laureles con los que orlan sus frentes los sevillanos". ${ }^{35}$

34 B.O.P de Huelva de 2 de agosto de 1843. Presidente Miguel Montiel.

35 B.O.P de Huelva, 2 de agosto de 1843. 
El 28 de julio de 1843 la Junta de Huelva decidió además transformar su carácter de provisional en propietaria, quedando integrada por los siguientes miembros:

\author{
Junta de Gobierno Propietario \\ Huelva, 28 DE JULIO DE I 843
}

PRESIDENTE:

VICEPRESIDENTE:

VOCALES:

\author{
Miguel Montiel \\ Gregorio Elías Toscano \\ Gregorio Arrayán y Vizcaíno \\ Pedro Pérez Ponce \\ Juan de Orta Rubio \\ Manuel González Vázquez \\ José Moreno \\ José Morón Ponce \\ León Antonio Coto \\ Patricio de la Corte
}

VOCAL SECRETARIO: Manuel Chaves

Entre los principios enarbolados y proclamados por la Junta onubense figuraban su adhesión a la Constitución de 1837, a la Monarquía de Isabel II, la independencia nacional y su identificación con el programa del Ministerio López. Y para mantenerlos consideraban prioritario "olvidar toda clase de resentimientos, abrazándonos como hermanos y confundiéndonos en una sola masa los que hasta ahora hemos combatido en las fistolas de los antiguos partidos políticos, que desgraciadamente han dividido a la Nación." ${ }^{36}$

Había finalizado la etapa de las Regencias y comenzaba el reinado de Isabel II.

\title{
Conclusión
}

Durante el verano de 1843, tras varios intentos fallidos, triunfó en Huelva el pronunciamiento contra la Regencia de Espartero. Una Junta Provisional de gobierno fue la encargada de sustituir las directrices de la Regencia, si bien las medidas adoptadas por dicha Junta se vieron dificultadas desde sus inicios por la carencia de recursos económicos y por la oposición, más o menos encubierta, a secundar sus iniciativas desde diversas localidades de la provincia. Los problemas derivados del mantenimiento del orden y la seguridad consumieron la mayor parte de los esfuerzos y preocupaciones de la Junta onubense.

Recibida ayuda militar desde Sevilla, los onubenses correspondieron a este apoyo acudiendo a auxiliar a la capital hispalense durante el bombardeo de VanHalen, convirtiéndose en testigos de la devastación, desolación y muertes ocasionados por los sitiadores. En el polo opuesto a la actuación de Huelva destaca la 
actitud de Cádiz, cuyas autoridades pro-esparteristas suministraron las bombas que los sitiadores arrojaron sobre Sevilla. Por su valerosa implicación Huelva se convirtió así en participe de los triunfos y honores de Sevilla, "la ciudad invicta". Este episodio cerró definitivamente la etapa de la Regencia del general Espartero. 